\title{
Fracasos en la adhesión
}

\author{
Esteban Herrera I.*
}

\section{RESUMEN}

Los fracasos en la adhesión se van a traducir en fallos a distintos niveles de las distintas interfases. Puede haber: (1) fallos adhesivos entre esmalte y material adhesivo, dentina y material adhesivo, resina compuesta y material adhesivo; o (2) fallos cohesivos en esmalte, dentina, resina compuesta, material adhesivo. Se examinan las distintas razones que los provocan así como los factores que influyen en las interfases estudiadas.

Palabras clave: Fallos de adhesión, interfase, fallos cohesivos.

\begin{abstract}
The failures in adhesion will turn into failures at different levels of the interface. There can be (1) adhesive failures, between the enamel and the adhesive material, dentine and the adhesive material, composite and the adhesive material; or (2) cohesive failures, in enamel, dentine, composite or adhesive material. The different reasons that lead to such situation as well as the aspects that influence the studied interfaces are analysed here.
\end{abstract}

Key words: Adhesion failures, interface, cohesive failures.

Aceptado para publicación: Octubre 2003.

* Profesora Asociada. Facultad de Odontología. Universidad de Sevilla.

Esteban Herrera I. Fracasos en la adhesión. Av. Odontoestomatol 2005; 21-2: 63-69.

Las distintas técnicas adhesivas suponen el empleo de una técnica compleja y además el conocimiento de los distintos sistemas adhesivos que vayan a ser usados por el clínico.

En los últimos años han aparecido en el mercado sistemas adhesivos, cada vez más fáciles de manejar, con menor número de pasos con objeto de simplificar la técnica. Hemos de tener en cuenta que cuantos más pasos y más complejidad haya para realizar un trabajo, más fácil es que se cometa algún error en alguno de los pasos realizados.

Por otro lado el conocimiento cada vez mayor de los comportamientos de las distintas estructuras dentarias, de los distintos materiales adhesivos y el estudio con técnicas microscópicas sofisticadas como el MET (microscopio electrónico de transmisión) el
ESSEM (Environmental Scanninig Electron Microscope) de las distintas interfases, nos proporcionan información detallada sobre los fallos a distintos niveles. Si sabemos donde se producen los fallos y como evitarlos estaremos en el camino adecuado para que nuestras restauraciones adhesivas tengan éxito y podamos proporcionar a nuestros pacientes, que en definitiva es de lo que se trata, salud bucodental.

Los fracasos en la adhesión se van a traducir en fallos a distintos niveles de las distintas interfases.

La localización de este fallo tiene importancia por dos motivos principalmente:

- Para la investigación, para saber la resistencia adhesiva a uno u otro nivel. 
- Por su importancia biológica, pues el fallo adhesivo según al nivel que sea tendrá repercusiones clínicas como la microfiltración, caries marginal y sensibilidad postoperatoria (1).

Distinguiremos los fallos adhesivos de los fallos cohesivos, de la siguiente manera:

Un fallo adhesivo sería aquel que ocurre entre dos estructuras distintas, es decir en la interfase entre ambas.

Un fallo cohesivo sería aquel que ocurre en el interior de la estructura del material.

Fallos adhesivos entre:

Esmalte y Material Adhesivo

Dentina y Material Adhesivo

Resina compuesta y Material Adhesivo Fig.1

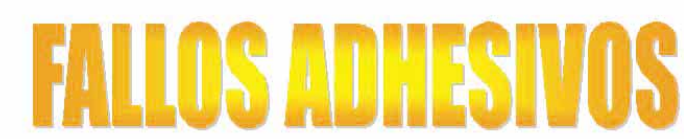

\section{*.- ESMALTE Y MATERIAL ADHESIVO \\ *.- DENTINA Y MATERIAL ADHESIVO \\ *.- COMPOSITE Y MATERIAL ADHESIVO}

Fig 1. Esquema de los fallos adhesivos.

Fallos cohesivos en:

Esmalte

Dentina

Resina compuesta

Material Adhesivo Fig.2

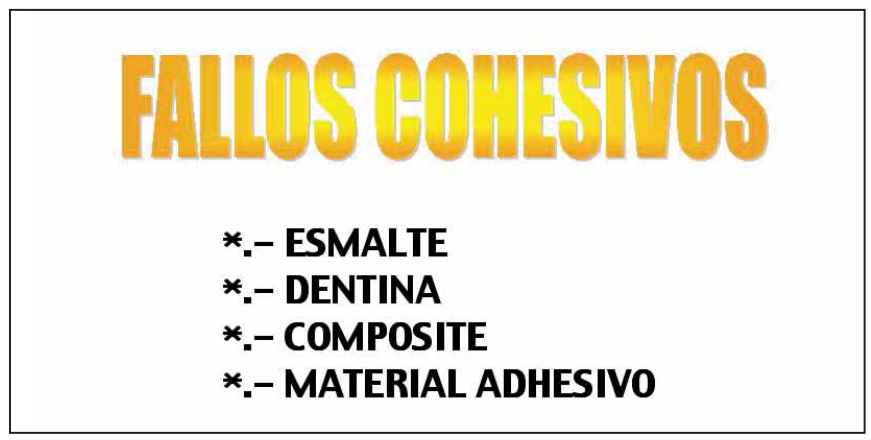

Fig. 2. Esquema de los fallos cohesivos

\section{FALLOS ADHESIVOS ENTRE ESMALTE Y MATERIAL ADHESIVO}

El esmalte por su estructura y su composición sigue siendo el sustrato ideal para la adhesión. Desde que Buonocore (2) en 1955 sentara las bases de la adhesión a esmalte, previo grabado con ácido ortofosfórico, los intentos por mejorarlo han resultado nulos. Se ha intentado tratar el esmalte con los distintos tipos de láser como el Erbium Yag o el láser Nd-YLF con resultados poco satisfactorios.

Para que no se produzcan fallos a este nivel es necesario que el esmalte tenga una energía superficial alta y el ácido y la resina adhesiva una humectabilidad también alta. En circunstancias normales el esmalte tiene una energía superficial baja esto le preserva su integridad estructural y además impide la adherencia bacteriana.

La falta de aislamiento correcto nos va a producir contaminación con saliva y con sangre y esto aumentará la energía superficial.

También la contaminación con aceite y agua por las conducciones de aire comprimido de los equipos van a alterar la energía superficial. Y por supuesto un esmalte sucio. Según distintos estudios uno de ellos publicado por la Dra. Osorio y colaboradores (3) la mejor manera de limpiar el esmalte sería con el aparato de bicarbonato. Las pastas de profilaxis producirían disminución de la energía superficial por el contenido en restos orgánicos. La limpieza del esmalte con bicarbonato tendría interés fundamentalmente cuando vayamos a colocar un sellador o brackets en ortodoncia, que de esta manera nos mejoraría la adhesión.

Falta de bisel correcto $\left(60\right.$ y $\left.80^{\circ}\right)$ : Es necesario decorticar y biselar correctamente el esmalte para mejorar la adhesión, eliminar la cutícula, aumentar la superficie de adhesión, eliminar la zona aprismática y mejorar la estética (4).

Una vez que tengamos el esmalte preparado realizaremos el grabado con ácido ortofosfórico al 37\% esperaremos 15 " y procederemos a realizar un lavado exaustivo de la superficie. Si este paso no lo realizamos correctamente podemos provocar un fallo 


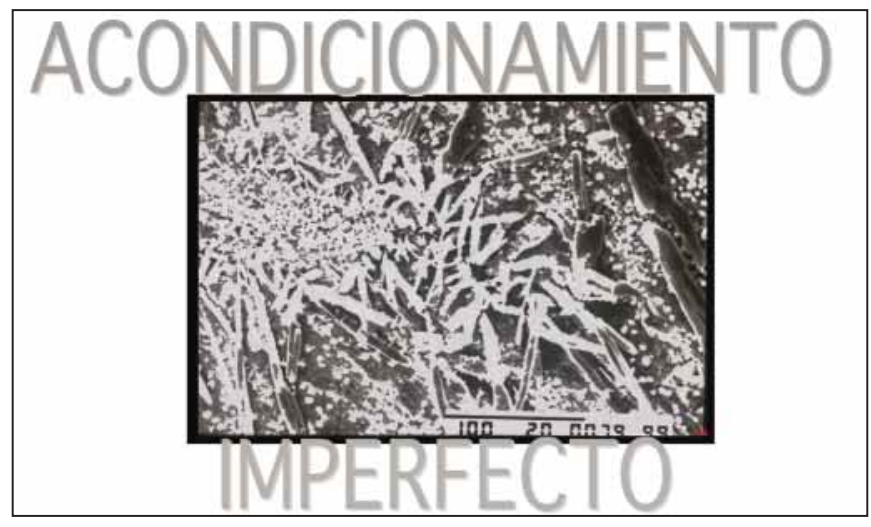

Fig. 3. Esmalte cubierto de cristales de hidroxiapatita y restos de materia inorganica. No ha sido lavado correctamente después del grabado con ácido ortofosfórico. Cortesía del Dr. Llamas Cadaval.

adhesivo porque las retenciones micromecánicas que habíamos realizado con el grabado aparecerán cubiertas de cristales de hidroxiapatita y restos de material inorgánico que impedirán la difusión del adhesivo de una manera correcta. Fig. 3.

A pesar de todo esto el esmalte es un buen substrato para la adhesión y con las precauciones anteriormente comentadas conseguiremos el éxito de la adhesión.

\section{FALLOS ADHESIVOS ENTRE DENTINA Y MATERIAL ADHESIVO}

La dentina ha sido y sigue siendo un reto para la adhesión, como lo demuestran los constates estudios que se siguen realizando para hacer de su estructura un buen substrato para la técnica adhesiva.

El aislamiento incorrecto nos impedirá una correcta adhesión por la contaminación de saliva y de sangre. Algunos adhesivos actuales que son fundamentalmente hidrofílicos parece que no son tan sensibles a la contaminación con saliva, pero no olvidemos que la saliva tiene proteínas y que estas nos van a alterar la energía superficial de la dentina. En cuanto a la contaminación con sangre puede resultar catastrófica. Destacaremos un estudio de Kaneshima y col. (5). En el que estudia las repercusiones de la contaminación con sangre en la resistencia adhesiva y encuentra que en la etapa del grabado no existen repercusiones importantes pues podemos volver a lavar, pero después de colocar el primer la resistencia disminuyó de

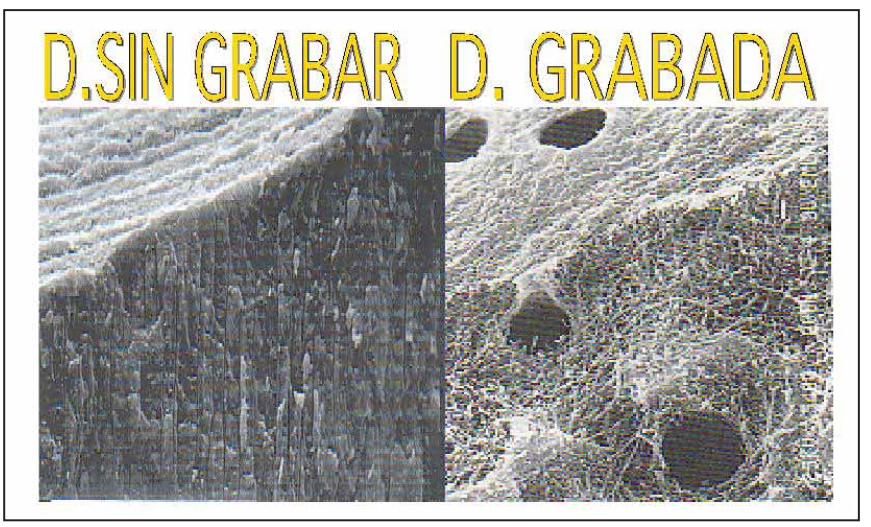

Fig. 4. Imágenes de microscopia electrónica que muestran una dentina, en la imagen de la derecha sin grabar cubierta por barrillo dentinario, en la imagen de la derecha la dentina grabada, mostrando el entramado de colágeno. Pashley.

una manera importante. Cuando la contaminación se produce entre las distintas capas de composite las repercusiones pueden ser muy negativas por la eliminación de la capa inhibida y por las tinciones.

\section{El acondicionamiento incorrecto de la superficie dentinaria:}

No nos podemos extender sobre este tema tan complejo y polémico, solamente comentar que parece que la técnica de grabado total que elimina el barrillo dentinario parece la más eficaz para aumentar y mejorar la adhesión. Pero lo importante aquí es elegir un sistema adhesivo actual con estudios serios de funcionamiento correcto(no debemos experimentar con los pacientes) y manejarlo correctamente, según el fabricante. La eliminación del barrillo con el ácido nos deja una superficie dentinaria con los túbulos abiertos y el entramado de fibras de colágeno expuestas. Fig. 4.

\section{Falta de formación de la capa híbrida o formación inadecuada de la misma:}

Hoy por hoy y mientras no se demuestre lo contrario(que todo puede suceder)la formación de la capa híbrida (6), descrita por Nakabayashi en 1982, parece ser esencial para la adhesión dentinaria. El adhesivo debe ser capaz de penetrar a través de ese entramado de fibras de colágeno ocupando todo el espesor de dentina desmineralizada formando un entramado tridimensional, para que la durabilidad de la 


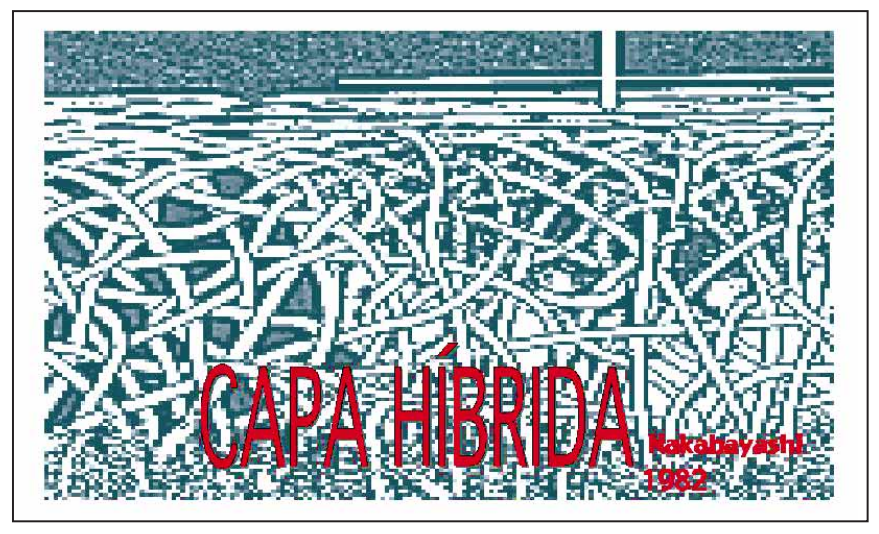

Fig. 5. Esquema que representa la capa híbrida con dos zonas, la derecha de la imagen representa una capa híbrida correcta en la que el adhesivo impregna toda la dentina desmineralizada y en la parte de la izquierda aparece una capa híbrida con colágeno sin impregnar por el adhesivo por existir en la zona superior un colágeno colapsado.

adhesión sea grande. Según Nakabayashi, la dentina desmineralizada debe ser de aproximadamente 1-2 micras para que se produzca la perfecta difusión del adhesivo. Fig. 5.

Nakajima y col. encontraron que en dentina afectada de caries la capa híbrida que se forma es más densa que en dentina normal quizás por la más alta desmineralización pero las fuerzas traccionales que se encontraron con distintos adhesivos eran menores que en dentina libre de caries.

\section{Falta de grado óptimo de humedad:}

Para que las fibras de colágeno se muestren receptivas, sueltas para recibir al material adhesivo es necesario que la dentina permanezca suficientemente húmeda, de lo contrario el colágeno se encuentra colapsado en su superficie y no se forma la capa híbrida. El problema es saber el grado de humedad óptimo. Se aconseja secar con papel secante, con algodón con la jeringa de aire a distancia con mucho cuidado, pero verdaderamente es difícil. Si dejamos agua en exceso podemos estar abocados al fracaso en la adhesión.

Si dejamos agua en exceso se formaran vesículas acuosas entre el adhesivo y la dentina o entre el primer y la resina hidrofóbica y esto nos proporcionará fallos a este nivel. Estas vesículas se denominan zonas hibroides y aparecen como zonas no densas al $\operatorname{MET}(7)$.
Este exceso de humedad también puede alterar la polimerización por competir el agua con la resina (8). Si decidimos optar por la técnica seca tendremos quizás menos problemas porque es más fácil de controlar la desecación de la dentina, desde un punto de vista clínico, pero necesitaremos imprimadores o adhesivos vehiculizados en medios acuosos que descompacten el colágeno para que se pueda formar una capa híbrida correcta. Estos adhesivos parece que obtienen cifras de fuerza adhesiva menores que los otros pero suficientes.

\section{Ausencia o formación inadecuada de los Tag de resina:}

La eficacia de los tag de resina en la adhesión está discutida, pero los distintos autores si parecen estar de acuerdo en que es más importante el número que la profundidad, por lo que son más importantes en la dentina profunda que en la superficial, ya que esta tiene mayor número de túbulos pero por el contrario tiene menos dentina intertubular y por tanto la capa híbrida será menor (9). En la dentina superficial el $n^{\circ}$ de túbulos es menor por lo que los tag de resina tendrán menor repercusión pero al existir más dentina intertubular la capa híbrida adquiere mayor importancia. También los tag de resina podrían ser un mecanismo de protección pulpar pues al tapar la entrada de los túbulos evitarían la invasión bacteriana y evitarían el dolor postoperatorio, al evitar el movimiento del fluido dentinario.

\section{Fallos por el solvente:}

Fundamentalmente los adhesivos van a vehiculizarse mediante acetona, alcohol y agua o mezclas de ellos. El solvente de acetona funciona bien con la técnica húmeda(descrita por Kanca y Gwinnett 1992) (10) el de alcohol funciona bien en húmeda y seca y el agua funciona bien en la técnica seca.

Con los adhesivos de alcohol y de acetona hemos de tener cuidado de no dejar los botes abiertos tras su uso pues se evaporan con gran facilidad y podría suceder que al cavo de unos cuantos usos nos fracasara la adhesión, porque la composición de estos ya sea completamente diferente a la correcta. Este 
problema parece solventarse con los adhesivos que se presentan en monodosis.

\section{Fallos en la correcta colocación del adhesivo:}

El adhesivo se ha de colocar con delicadeza en el esmalte pues los prismas están descalcificados y podrían desprenderse.

En cambio en la dentina hemos de realizar movimientos de frotamiento para permitir la interdifusión del adhesivo. Además los monómeros de esta manera parece que son aspirados e incorporados al entramado de colágeno para formar la capa híbrida. Esta técnica produce al microscopio una imagen que se ha denominado "alfombra de lana"(shag carpet)porque el colágeno aparece verticalizado y entrelazado (11).

Es importante colocar una capa uniforme y de cierto espesor, para que amortigüe las tensiones provocadas por el composite y por la masticación. Con algunos adhesivos es necesario colocar varias capas del mismo.

Hemos dicho que es interesante que el adhesivo tenga espesor de capa para amortiguar tensiones, pues los fabricantes han sacado al mercado adhesivos con microrrelleno o nanorrelleno que nos van a proporcionar dicho espesor, pero son más viscosos y esto podría impedir el paso del adhesivo al interior de la capa híbrida y al interior del túbulo dentinario. Los fabricantes dicen que no, pues están hechos con nanoparticulas que permiten la perfecta difusión.

Lo cierto es que reducen la contracción de polimerización y parece ser que la microfiltración (12).

Es también importante para evitar fallos, una vez colocado el adhesivo, esperar entre diez y quince segundos antes de eliminar el exceso de solvente con la jeringa de aire y antes de la polimerización del mismo, para darle tiempo al adhesivo para que penetre correctamente en el interior de la capa de colágeno.

\section{Polimerización incorrecta:}

Es muy importante polimerizar correctamente durante 20" pues de no ser así se produciría la desadaptación entre el adhesivo y la dentina.
Es importante reseñar que las lámparas de plasma solo cubren las longitudes de onda entre 445 y 495 $\mathrm{nm}$. mientras que las lámparas halógenas convencionales cubren 400 y $600 \mathrm{~nm}$. cubriendo todo el espectro de las canforoquinonas o de otros iniciadores de los adhesivos fotopolimerizables.

Las consecuencias de los fallos a este nivel van a ser la microfiltración y por tanto la caries recurrente y el fracaso final de nuestras restauraciones adhesivas

\section{FALLOS ADHESIVOS ENTRE RESINA COMPUESTA Y MATERIAL ADHESIVO}

Básicamente a este nivel para evitar los fallos hemos de evitar la contaminación con saliva y con sangre por todo lo que hemos contado anteriormente.

Conviene que nuestros adhesivos lleven en su composición resinas hidrofóficas pues mejoran la unión al composite que es un material hidrofobo.

Es necesaria la correcta polimerización del adhesivo. Puede ocurrir la desadaptación de ambas superficies sobre todo con composites viscosos, en este caso quizás convendría colocar antes una capa de un composite fluido para mejorar esta adaptación y amortiguar tensiones.

La contracción de polimerización del composite puede ser un factor muy importante para la desadaptación entre los dos materiales. Hemos de intentar que el composite se deforme antes de que traccione del adhesivo, para ello tendremos que tener un factor de conversión lo más favorable posible. Si esto no es posible lo hemos de solventar con la técnica incremental, en lo que respecta a la manipulación del composite.

El exceso de agua puede ser muy negativo para la unión del adhesivo y el composite, como han estudiado Pashley y col.,dado el carácter hidrófobo del composite .Este exceso de agua es más frecuente en los adhesivos que contienen agua en su composición, porque es más difícil eliminar el agua que el otro tipo de solventes. 


\section{FALLO COHESIVO EN ESMALTE Y DENTINA}

Las causas suelen ser por desmineralización excesiva causada fundamentalmente por exceso de tiempo de grabado ácido o por utilizar ácidos muy fuertes o de concentración elevada.

Esta desmineralización también puede ser debida al propio proceso cariogénico, ya que no hemos de olvidar que tratamos dientes que sufren caries.

Otra causa de fallo cohesivo se debe a la tracción excesiva del composite cuando polimeriza, si encuentra un esmalte debilitado y desmineralizado es factible que lo rompa.

Y por último otra causa de fallo cohesivo son los traumatismos.

\section{FALLO COHESIVO EN RESINA COMPUESTA}

Las causas más frecuentes para este tipo de fallos van a ser:

- Contaminación de saliva y de sangre entre las distintas capas de composite cuyas implicaciones van a ser la pérdida de la capa inhibida y la pigmentación.

- La técnica incorrecta sobre todo por polimerizar capas demasiado gruesas, implicará el fallo cohesivo.

- Por eliminación de la capa inhibida. La capa inhibida es una capa de $15 \mathrm{~mm}$. de espesor que resulta trascendental para la unión entre las distintas capas de composite y que se forma en presencia de oxigeno.

- Por último los traumatismos también podrían ser causa de un fallo cohesivo.

\section{FALLOS COHESIVOS EN EL MATERIAL ADHESIVO}

Aquí a veces es difícil discernir entre un fallo cohesivo y un fallo adhesivo.
Parece que las zonas donde más frecuente es el fallo son la capa superficial de la capa híbrida y la zona profunda de la misma.

Las causas no son bien conocidas, pues hemos de tener en cuenta que se trata de una zona de aproximadamente 0,5 y $1 \mathrm{~mm}$. Debido a este pequeño tamaño es difícil su estudio, incluso son difíciles de interpretar las imágenes de microscopía electrónica.

En la zona superficial los fallos son debidos a un colapso de la zona superficial del colágeno y también parece que existe un colágeno desnaturalizado resistente al ácido clorhídrico y a las cólagenasas (13), esta capa parece que no interfiere en la difusión de los monómeros pero deja una capa más débil a nivel superficial de la capa híbrida.

Otra causa podría ser la falta de distribución uniforme de los monómeros a través de esos canales de difusión tan estrechos y largos entre las fibras de colágeno. El peso molecular de MMA es de 100, el del BisGMA 511 estos monómeros no encuentran problemas para difundir pero el peso molecular de PMMA es de 400.000 y estos si tienen dificultad para difundir por los canales de $20 \mathrm{~nm}$. que existen entre las fibras de colágeno (14).

Las causa de fallo en la zona profunda de la capa híbrida parece ser la mayor afinidad de los monómeros por las paredes de los túbulos, quizás por su mayor concentración de agua. Dan una imagen como de champiñón al microscopio electrónico de transmisión (15).

También puede ser causa de fallo a este nivel la aparición de gap que debilitan e hidrolizan el colágeno.

Por último, aunque es seguro que existirán muchas más causas aun no estudiadas, las zonas hibroides pueden alterar la capa híbrida pues pueden aparecer entre el imprimador y la resina hidrofóbica.

Las repercusiones clínicas de los fallos a este nivel serían la nanofiltración y el dolor. 


\section{BIBLIOGRAFÍA}

1. Jiménez Planas, A. Llamas R. Y col. Sistemas adhesivos. J. M. De Vega (Ed): Materiales en odontología. Edic 1 ${ }^{a}$ Madrid Ed.Ibergráficas, S.A. 1996 pag. 315-32.

2. Buonocore MG.A simple method of increasing the adhesion of acrilic materials to enamel surface. J Dent Res 1955; 34: 849.

3. Osorio,R. Y col. Métodos de profilaxis. Estudio in vitro de las variaciones en la humectabilidad de tres ácidos ortofosfóricos. Avances 1996 JulAgo, Vol. 12 N 6 : 419-26.

4. Uribe, J. Y col. Restauraciones con resinas compuestas en el sector anterior. Uribe, J. (Ed): Operatoria dental ciencia y práctica. Madrid. Ed. Avances. S.L. 1990. pág. 231-306.

5. Kaneshima T, y col. The influence of blood contamination on bond strengths between dentin and adhesive resin cement. 77: Open Dent 2000 May-Jun; 25 (3): 195-201.

6. Nakabayashi et al.The promotion of adhesion by the infiltration of monomers into thooth substrates. J.Biomed Mater Res, 1982; 16: 265-73.

7. Perdigao $\mathrm{J} y \mathrm{col}$. The interaction of adhesive systems with human dentin. Am J Dent, 1996; 16773.
8. Nakabayashi ,Pashley. Hibridation of Dental hard Tissue.Tokio Quintessence Publising. Ed C.O., Limited 1998.

9. Nakabayashi, Pashley. Hibridation of dental hard tissue. Tokio Quintessence Publishing. Ed C.O, Limited 1998.

10. Kanca et al.Improving bond strength through acid etching of dentin and bonding to wet dentin surfaces. J Am Den Assoc, 1992; 123: 39-41.

11. Van Meerbeek et al The clinical performance of adhesive. J Dent, 1997.

12. Swift E J Jr, et al Effect of low-viscosity resin on the performance of dental adhesives. Am J Dent 1996; 9:100-4.

13. Usami Y,Fukushima M, et al.Ultaestructure of the cut acid treated dentin surface. Dent res 1990; 68: 203.

14. Van Meerbeek B, et al Comparatie SEM and Tem examination of the ultraestructure of the resindentin interdiffusion zone. J Dent Res 1993; 11: 995-73.

15. Nakabayashi, Pashley.Hibridation od dental hard tissue.Tokio Quintessence Publising. Ed. C.O. Limited 1998. 